\title{
Bekkenbanden voor acute stabilisatie van instabiele bekkenfracturen
}

\author{
S.P. Knops ${ }^{1}$ \\ P. Patka ${ }^{2}$ \\ T. Schepers ${ }^{3}$ \\ E.M.M. van Lieshout ${ }^{4}$
}

\section{Samenvatting}

Bekkenbanden zijn ontwikkeld voor de eerste behandeling van instabiele bekkenringfracturen in de prehospitale fase. Deze behandeling is gericht op het beperken van het inwendig bloedverlies door het verkleinen van het bij bekkenfracturen toegenomen bekkenvolume en het stabiliseren van de fractuurdelen. Het effect van commercieel verkrijgbare bekkenbanden op de reductie van de symphysis pubisdiastase en de hemodynamische stabiliteit is aangetoond. Het langdurig gebruik van bekkenbanden wordt ontraden wegens toegenomen risico op het ontwikkelen van decubitus. Met name langdurige immobilisatie met een bekkenband op een traumaplank dient voorkomen te worden. In dit artikel wordt een aantal verschillende bekkenbanden besproken en wordt een casus gepresenteerd.

\section{Inleiding}

Bekkenbanden worden in de traumachirurgie gebruikt voor de eerste behandeling van instabiele bekkenringfracturen. De meeste patiënten die overlijden na een hoogenergetisch trauma (HET), overlijden ten gevolge van hypovolemische shock, omdat de resuscitatie in 'the golden hour' faalt. Naast bloedingen vanuit de fractuurvlakken (spongieus bot) kunnen bloedingen vanuit arteriële laesies en de veneuze plexus bij een patiënt met een bekkenringfractuur voor ernstige complicaties zorgen. Prehospitale resuscitatie en behandeling van instabiele bekkenringfracturen gaat volgens de bekende principes van de Advanced Trauma Life Support (ATLS) ${ }^{1}$ en Damage Control Surgery (DCS). Doel is het behandelen van de hypovolemische shock en het voorkómen van hypothermie, metabole acidose

\footnotetext{
${ }^{1}$ arts-onderzoeker, afdeling Heelkunde-Traumatologie

2 traumachirurg, hoofd Spoedeisende Hulp

${ }^{3}$ CHIVO Traumachirurgie, afdeling Heelkunde-Traumatologie

${ }^{4}$ onderzoekscoördinator, afdeling Heelkunde-Traumatologie

Alle auteurs zijn werkzaam in het Erasmus MC Rotterdam.
} 
en stollingsstoornissen, ook wel 'lethal triad' genoemd. Het voorkómen van hypovolemische shock gebeurt onder andere door stabilisatie van de bekkenring in geval van een fractuur. Deze stabilisatie is gericht op het beperken van het inwendig bloedverlies door het verkleinen van het bij bekkenfracturen toegenomen bekkenvolume, het reduceren van de diastase van het os pubis en het stabiliseren van de fractuurdelen. Dit wordt bereikt door zo snel mogelijk na het trauma uitwendige circumferentiële compressie van de bekkenring aan te brengen. Daarnaast hebben bekkenbanden een functie bij het reduceren van pijn en beweging gedurende transport en transfers. Bekkenbanden zijn geschikt als tijdelijke behandeling, totdat definitieve stabilisatie en fixatie kan plaatsvinden.

In dit artikel wordt de geschiedenis en de ontwikkeling van bekkenbanden besproken en een overzicht van de huidige commercieel verkrijgbare banden gegeven. Daarnaast worden de indicatiestelling en toepassing toegelicht. De effectiviteit en het risico op complicaties worden kort vermeld. Tot slot zal aan de hand van een casus het gebruik van een bekkenband geïllustreerd worden.

\section{Classificatie van bekkenringfracturen}

Voor een beter begrip van het principe van stabilisatie van bekkenringfracturen is kennis van de classificatie van de verschillende typen fracturen en de onderliggende mechanismen van belang. Tile introduceerde de behandeling van bekkenringfracturen, die direct gerelateerd is aan de mate en richting van de instabiliteit. ${ }^{2}$ Fracturen worden ingedeeld door de belangrijkste fractuur te classificeren. De pathomechanische Tile-classificatie is gebaseerd op de richting van de kracht die het letsel veroorzaakt en de progressieve instabiliteit van de bekkenring. De Tile-classificatie werd aangepast door de Arbeitsgemeinschaft für Osteosynthesefragen (AO) en heeft bekkenfracturen onderverdeeld in 3 groepen:

- Type-A-fracturen zijn stabiele bekkenringfracturen, zoals een ramus superior fractuur.

- Type-B-fracturen zijn open-boekbekkenringfracturen (B1), die worden veroorzaakt door anterieur-posterieure compressie en externe rotatie, de laterale-compressiefracturen (B2), die uiteraard door lateraal inwerkende krachten worden veroorzaakt en bilaterale letsels (B3). Deze bekkenringfracturen zijn rotatoir instabiel, maar verticaal stabiel.

- Type-C-fracturen zijn compleet instabiele bekkenringfracturen, die veelal worden veroorzaakt door verticaal afschuivende shearkrachten. Deze fracturen zijn zowel rotatoir als verticaal instabiel.

Een (relatieve) contra-indicatie voor het aanbrengen van een bekkenband is een fractuur van het laterale-compressietype. Bij een dergelijke fractuur bestaat een risico op overcompressie en daarbij zou secundair letsel aan de blaas kunnen ontstaan. 


\section{Geschiedenis en ontwikkelingen}

Aan de ontwikkeling van bekkenbanden is een aantal interessante stabilisatiemethoden voorafgegaan. Luitenant-kolonel Burton Kaplan, chirurg in het Amerikaanse leger in Vietnam ontwikkelde in 1972 de military antishock trousers voor het hemodynamisch stabiliseren en transporteren van patiënten met hemorragische shock. In de daaropvolgende jaren werden de medical antishock trouser (MAST) en pneumatic antishock garment (PASG) gebruikt. Gerandomiseerde trials toonden echter geen overlevingswinst, maar wel een toename van complicaties, zoals het abdominale compartimentsyndroom en druknecrose. ${ }^{3}$ Bovendien wordt bij het gebruik van MAST de chirurgische toegang tot het abdomen, de liesregio en de onderste extremiteiten belemmerd. Het gebruik van MAST is daarom obsoleet geworden.

Circumferentiële compressie van de bekkenregio kan ook worden verkregen door het aanbrengen van een sluitlaken. ${ }^{4-6}$ Hierbij wordt een bedlaken rondom het bekken geplaatst ter hoogte van de grote trochanters en vervolgens geknoopt. Met aanvullende interne rotatie en tapen van de onderste extremiteiten zorgt men voor toename van de stabilisatie. ${ }^{7}$ Dit is in het bijzonder bij patiënten met morbide adipositas een bruikbaar alternatief.

Bekkenbanden of pelvic circumferential compression devices (PCCD's), bedoeld voor het prehospitaal behandelen van instabiele bekkenringfracturen werden voor het eerst beschreven in 1999. ${ }^{8}$ Inmiddels zijn deze bekkenbanden in meerdere vormen als commerciële binders, belts, slings en wraps verkrijgbaar. ${ }^{9-12}$ De in dit artikel besproken bekkenbanden moeten niet verward worden met stabiliserende behandelingen van niet-traumatische (o.a. zwangerschapsgerelateerde) bekkeninstabiliteit. In Nederland zijn de bekkenbanden reeds geruime tijd beschikbaar voor het mobiel medisch team (MMT) in de traumahelikopters en in ambulances, maar ook op de Spoedeisende Hulp (SEH) van de ziekenhuizen.

\section{Een overzicht van de bekkenbanden}

Huidige bekkenbanden, zoals de Pelvic Binder ${ }^{\circledR}$, de SAM-Sling ${ }^{\circledR}$ en de T-POD ${ }^{\circledR}$ (fig. 1) zijn eenvoudig in gebruik en kunnen bij een patiënt in rugligging snel (30 seconden) worden aangebracht. Deze bekkenbanden zijn röntgendoorlaatbaar en kunnen veilig in de MRI gebruikt worden. Aanvullende diagnostiek wordt dus niet gecompromitteerd door een prehospitaal aangebrachte bekkenband. De Pelvic Binder ${ }^{\circledR}$ (Pelvic Binder Inc., Dallas, TX, USA) is 'one size fits all' en heeft als sluitingsmechanisme een schoenvetersysteem dat eveneens met klittenband aan de band moet worden bevestigd. Adequate compressie wordt eenvoudig verkregen door bij het aantrekken van de bekkenband ten minste 2 vingers tussen de band en de patiënt te plaatsen.

De SAM-Sling ${ }^{\circledR}$ (SAM Medical Products, Newport, OR, USA) is beschikbaar in de maten 'extra small', 'standard' en 'extra large'. Het smalle ontwerp van de band laat meer ruimte over voor klinische diagnostiek en toegang tot het abdomen. De SAM-Sling ${ }^{\circledR}$ moet met 2 handen in 
tegengestelde richting worden aangetrokken en is uitgerust met een systeem dat feedback geeft wanneer een vastgestelde trekkracht $(150 \mathrm{~N})$ is verkregen voor adequate volumereductie. Hiermee wordt getracht overcompressie en overreductie te voorkomen.

Ook de T-POD ${ }^{\circledR}$ (Trauma Pelvic Orthotic Device: Bio Cybernetics International, La Verne, CA, USA) is 'one size fits all'. Deze band moet op maat geknipt worden, waarbij een opening van ongeveer 15$20 \mathrm{~cm}$ blijft bestaan. Het sluitingsmechanisme moet met klittenband aan de band bevestigd worden en bestaat uit een 'pulley' systeem dat zorgt voor simultane circumferentiële compressie. Net als bij de Pelvic Binder ${ }^{\circledR}$ wordt adequate compressie met de T-POD ${ }^{\circledR}$ eenvoudig verkregen door bij het aantrekken van de bekkenband ten minste 2 vingers tussen de band en de patiënt te plaatsen.

Figuur 1. a) Pelvic Binder ${ }^{\circledR}$; b) SAM-Sling ${ }^{\circledR}$; c) T-POD ${ }^{\circledR}$.

\section{Indicatiestelling en toepassing}

Bij verdenking op een bekkenfractuur op basis van het traumamechanisme is de indicatie voor het prehospitaal aanbrengen van een bekkenband in principe al gesteld. Vooral als een patiënt daarbij hemodynamisch instabiel is en een hypovolemische shock dreigt. Bij traumascreening mag een adequaat lichamelijk onderzoek niet ontbreken. De beoordeling van een beenlengteverschil of rotatie in een van de onderste extremiteiten is van belang. Verder moet controle van asdrukpijn plaatsvinden bij laterale compressie en bij voor-achterwaartse compressie, en controle van instabiliteit bij binnenen buitenwaartse druk op de spinae iliaca anterior superior ('rocking the pelvis'). Bij aanwijzingen voor instabiliteit moet een bekkenband aangelegd worden. De stabiliteit mag slechts eenmalig te worden getest, vanwege het risico op secundaire dislocatie en het daarmee geassocieerde risico op bloedingen. Wanneer bij lichamelijk onderzoek aanwijzingen worden gevonden voor een bekkenringfractuur moet een bekkenband aangelegd worden. De meest effectieve compressie wordt bereikt indien de bekkenband op het niveau van de grote trochanters wordt aangebracht (en niet ter hoogte van het os ilium). ${ }^{13,14}$

\section{Effectiviteit}

Een overzicht van de effectiviteit van bekkenbanden voor de behandeling van instabiele bekkenringfracturen is verzorgd in een recent gepubliceerd systematisch review. ${ }^{15}$ In dit review wordt het gebruik besproken van commercieel beschikbare bekkenbanden voor acute stabilisatie van bekkenringfracturen, zoals de Pelvic Binder ${ }^{\circledR}$, de SAM-Sling ${ }^{\circledR}$ en de T-POD ${ }^{\circledR}$. Er zijn geen systematic reviews (niveau I) en gerandomiseerde klinische studies (niveau II) uitgevoerd naar de klinische effectiviteit van deze bekkenbanden, maar wel cohortstudies en case-controlstudies (niveau III-IV). Deze laatste laten zien dat bekkenbanden effectief zijn voor het reduceren van het bekkenvolume, het 
reduceren van de diastase en het stabiliseren van de fractuurdelen. Een aantal illustratieve studies uit deze review en een aantal daarna verschenen studies wordt hierna kort vermeld.

\section{Reductie van het bekkenvolume en transfusiebehoefte}

Zoals eerder aangegeven is het verkleinen van het toegenomen bekkenvolume, reductie van het inwendig bloedverlies en afname van de transfusiebehoefte een belangrijke maat voor de effectiviteit van bekkenbanden. Het is angetoond dat bij instabiele bekkenringfracturen (Tile type B en C) de T$\mathrm{POD}^{\circledR}$ in de acute fase een compressief effect heeft op het bekkenvolume en de hemodynamische stabiliteit, op grond van metingen van de circulatoire respons voor en na het aanbrengen van de T$\mathrm{POD}^{\circledR} .{ }^{16}$ Patiënten na circumferentiële compressie met een bekkenband hebben een geringere transfusiebehoefte en een geringer risico op het ontwikkelen van infectieuze complicaties, zoals een pneumonie. ${ }^{9}$ Het bewijs dat het gebruik van bekkenbanden een significante reductie geeft van bloedingen en mortaliteit, zoals geassocieerd met bekkenringfracturen, is niet eenduidig. ${ }^{17}$ Het gebruik van bekkenbanden in een ziekenhuis waar acute arteriële embolisatie tot de behandelingsmogelijkheden behoort zou daarom niet altijd de eerste keus zijn.

\section{Reductie van de diastase}

Een andere belangrijke maat voor effectiviteit van bekkenbanden is de kwaliteit van de reductie van de diastase van fracturen van de symphysis pubis en de sacro-iliacale gewrichten. De verschillende bekkenbanden bewerkstelligen adequate reductie van de bekkenring in partieel stabiele (Tile type B) en instabiele (Tile type $\mathrm{C}$ ) bekkenringfracturen en geven geen risico op ongewenste overreductie. De noodzakelijke trekkracht voor het verkrijgen van adequate reductie is het laagst voor de T-POD ${ }^{\circledR}(40$ N). ${ }^{18}$ In een kadaverstudie is bovendien angetoond dat de T-POD ${ }^{\circledR}$ een betere reductie geeft van de diastase (Tile type B1) ten opzichte van het sluitlaken. ${ }^{19}$ In een cohortstudie bleek de reductie van de symphysis pubisdiastase met het gebruik van bekkenbanden vergelijkbaar met de reductie die bij definitieve operatieve fixatie wordt verkregen. ${ }^{11}$

\section{Stabiliteit}

Ten slotte is de effectiviteit van bekkenbanden afhankelijk van de stabiliteit en moet het effect van bekkenbanden worden vergeleken met andere (tijdelijke) fixatieopties. De stabiliteit die wordt verkregen met een prototype bekkenband is vergelijkbaar met de stabiliteit van een 'C-clamp' (gesloten reductie door middel van percutaan geplaatste pinnen en een extern frame). ${ }^{13}$ De stabiliteit die wordt verkregen met een bekkenband is echter maar een derde van de flexie-extensiestabiliteit en een tiende van de interne-externe rotatiestabiliteit die kan worden verkregen met een externe fixateur. Het aanbrengen van een C-clamp en een externe fixateur vereist echter kennis van de techniek en 
ervaring en is niet mogelijk in prehospitale setting. Daarentegen is het gebruik van een bekkenband niet-invasief en kan wel eenvoudig prehospitaal plaatsvinden.

\section{Complicaties}

Het gebruik van bekkenbanden wordt beperkt door traumatische afwijkingen aan de huid en weke delen, zoals ernstige schaaf- en brandwonden, deglovement en morel-lavalléelaesies. Een morellavalléelaesie is een gesloten interne deglovement van het subcutane weefsel, gevuld met bloed en sereus vocht, die bij bekkenringfracturen met name optreedt ter hoogte van het sacrum en het dorsale bekken. Over complicaties ten gevólge van bekkenbanden en de ernst van deze complicaties is vrijwel niets bekend. Beschikbare casuïstiek suggereert een risico op het ontwikkelen van decubitus en huidnecrose. ${ }^{20,21}$ Een bijzondere complicatie is bilaterale peroneus parese na het aanleggen van een bekkenband. ${ }^{22}$ In de literatuur zijn geen andere ernstige complicaties veroorzaakt door het gebruik van bekkenbanden beschreven.

Weefselschade zou kunnen optreden wanneer een continue druk op de huid bestaat, hoger dan 9,3 kPa (9300 N/ $\mathrm{m}^{2}$, corresponderend met $70 \mathrm{mmHg}$ ), gedurende 2-3 uur. Drukkarakteristieken bij het gebruik van een bekkenband (Pelvic Binder ${ }^{\circledR}$ ) zijn eerder bestudeerd.$^{10,23,24}$ Verschillen in bandontwerp en functionele karakteristieken zoals de verschillende sluitingsmechanismen, resulteren in een specifiek drukpatroon. Als de aanwijzingen van de producenten van de banden worden gevolgd, is er een duidelijk risico op het overschrijden van het niveau waarop weefselschade is te verwachten. ${ }^{23} \mathrm{Bij}$ langdurig gebruik van deze banden valt te verwachten dat deze banden een risico vormen op het ontwikkelen van decubitus. Bij langdurig gebruik van bekkenbanden is daarom frequente controle van de huid geïndiceerd. Circumferentiële compressie van het bekken door middel van een bekkenband, in combinatie met immobilisatie op een traumaplank, zorgt voor een aanzienlijke overschrijding van de weefseldruk. ${ }^{24}$ Hierbij bestaat het risico op het ontstaan van decubitus. Clinici moeten zich bewust zijn van deze potentieel schadelijke effecten die zijn geassocieerd met het gebruik van bekkenbanden. Het faciliteren van een vroege transfer van de traumaplank naar een ziekenhuismatras is daarbij essentieel, omdat het risico op decubitus na overtillen significant daalt.

\section{Casus}

Een 51-jarige man werd bij aankomst op de afdeling Spoedeisende Hulp, na een hoog energetisch trauma als gevolg van het neerstorten van een helikopter, onderzocht en behandeld volgens de ATLSprincipes. De patiënt was volledig geïmmobiliseerd, geïntubeerd en hemodynamisch instabiel op basis van een hypovolemische shock. Aanvullend onderzoek in het kader van de traumascreening toonde multipele fracturen, waaronder een open-boek bekkenringfractuur (fig. 2a) met diastase van de sacroiliacale gewrichten en de symphysis pubis, proximale femurfracturen beiderzijds en multiple instabiele wervelfracturen. 
Op de traumakamer werd de aangelegde bekkenband (T-POD ${ }^{\circledR}$ ) aangesnoerd en was er een evidente reductie van de symphysis pubisdiastase waarneembaar (fig. $2 b$ ). Volgens de damage control surgery principes werd een fixateur externe op het bekken geplaatst. Hiertoe werden twee schanze pennen in het ilium beiderzijds geplaatst, waarna het bekken werd gereponeerd. Daarna werden zowel in het rechter- als in het linker femur twee schanze pennen en een body geplaatst vanaf de bekkenfixateur tot aan de beide femora. Patiënt reageerde goed op vulling en werd hemodynamisch stabiel. Het urethrogram toonde een urethraletsel waarvoor een suprapubische katheter werd ingebracht.

\section{In perspectief}

Bekkenbanden hebben een plaats ingenomen in de prehospitale en acute behandeling van traumapatiënten met een instabiele bekkenfractuur. Bij de ontwikkeling van een nieuwe generatie bekkenbanden zijn het stabiliserende vermogen en het comfort van belang en moet het risico op het ontwikkelen van decubitus beperkt worden.

Prospectieve gerandomiseerde klinische studies zijn nodig om de klinische relevantie en veiligheid van bekkenbanden verder te onderzoeken. Uiteindelijk zal deze kennis bijdragen aan het ontwikkelen van evidence-based richtlijnen voor effectief en veilig gebruik van bekkenbanden.

\section{Literatuur}

1. American College of Surgeons. Advanced trauma life support for doctors, ATLS Guidelines. 8th ed. Chicago, USA, 2008.

2. Tile M. Pelvic ring fractures: should they be fixed? J Bone Joint Surg Br. 1988;70(1):1-12.

3. Aprahamian C, Gessert G, Bandyk DF, e.a. MAST-associated compartment syndrome (MACS): a review. J Trauma. 1989;29(5):549-55.

4. Nunn T, Cosker TD, Bose D, Pallister I. Immediate application of improvised pelvic binder as first step in extended resuscitation from life-threatening hypovolaemic shock in conscious patients with unstable pelvic injuries. Injury. 2007;38(1):125-8.

5. Routt ML, Jr., Falicov A, Woodhouse E, e.a. Circumferential pelvic antishock sheeting: a temporary resuscitation aid. J Orthop Trauma. 2006;20(1 Suppl):S3-6.

6. Simpson T, Krieg JC, Heuer F, e.a. Stabilization of pelvic ring disruptions with a circumferential sheet. J Trauma. 2002;52(1):158-61.

7. Gardner MJ, Parada S, Chip Routt ML, Jr. Internal rotation and taping of the lower extremities for closed pelvic reduction. J Orthop Trauma. 2009;23(5):361-4.

8. Vermeulen B, Peter R, Hoffmeyer P, Unger PF. Prehospital stabilization of pelvic dislocations: a new strap belt to provide temporary hemodynamic stabilization. Swiss Surg. 1999;5(2):43-6.

9. Croce MA, Magnotti LJ, Savage SA, e.a. Emergent pelvic fixation in patients with exsanguinating pelvic fractures. J Am Coll Surg. 2007;204(5):935-9; discussion 940-2. 
10. Jowett AJ, Bowyer GW. Pressure characteristics of pelvic binders. Injury. 2007;38(1):118-21.

11. Krieg JC, Mohr M, Ellis TJ, e.a. Emergent stabilization of pelvic ring injuries by controlled circumferential compression: a clinical trial. J Trauma. 2005;59(3):659-64.

12. Ward LD, Morandi MM, Pearse M, e.a. The immediate treatment of pelvic ring disruption with the pelvic stabilizer. Bull Hosp Jt Dis. 1997;56(2):104-6.

13. Bottlang M, Krieg JC, Mohr M, e.a. Emergent management of pelvic ring fractures with use of circumferential compression. J Bone Joint Surg Am. 2002;84-A Suppl 2:43-7.

14. Bottlang M, Simpson T, Sigg J, e.a. Noninvasive reduction of open-book pelvic fractures by circumferential compression. J Orthop Trauma. 2002;16(6):367-73.

15. Spanjersberg WR, Knops SP, Schep NWL, e.a. Effectiveness and complications of pelvic circumferential compression devices in patients with unstable pelvic fractures: a systematic review of literature. Injury. 2009;40(10):1031-5.

16. Tan EC, van Stigt SF, Vugt AB van. Effect of a new pelvic stabilizer (T-POD) on reduction of pelvic volume and haemodynamic stability in unstable pelvic fractures. Injury. 2010;41(7):101721.

17. Ghaemmaghami V, Sperry J, Gunst M, e.a. Effects of early use of external pelvic compression on transfusion requirements and mortality in pelvic fractures. Am J Surg. 2007;194(6):720-3; discussion 723.

18. Knops SP, Schep NWL, Spoor CW, e.a. Comparison of three different pelvic circumferential compression devices: a biomechanical cadaver study. J Bone Joint Surg Am. 2011;93(3):230-40.

19. DeAngelis NA, Wixted JJ, Drew J, e.a. Use of the trauma pelvic orthotic device (T-POD) for provisional stabilisation of anterior-posterior compression type pelvic fractures: a cadaveric study. Injury. 2008;39(8):903-6.

20. Krieg JC, Mohr M, Mirza AJ, e.a. Pelvic circumferential compression in the presence of softtissue injuries: a case report. J Trauma. 2005;59(2):470-2.

21. Schaller TM, Sims S, Maxian T. Skin breakdown following circumferential pelvic antishock sheeting: a case report. J Orthop Trauma. 2005;19(9):661-5.

22. Shank JR, Morgan SJ, Smith WR, e.a. Bilateral peroneal nerve palsy following emergent stabilization of a pelvic ring injury. J Orthop Trauma. 2003;17(1):67-70.

23. Knops SP, Riel MPJM van, Goossens RHM, e.a. Measurements of the exerted pressure by pelvic circumferential compression devices. Open Orthop J. 2010;4:101-6.

24. Knops SP, Lieshout EMM van, Spanjersberg WR, e.a. Randomised clinical trial comparing pressure characteristics of pelvic circumferential compression devices in healthy volunteers. Injury. 2010 [Epub ahead of print]. 


\section{Abstract}

Pelvic circumferential compression devices have been developed for initial treatment of unstable pelvic ring fractures in the prehospital situation. The treatment is aimed at achieving tamponade by reducing the increased pelvic volume and reducing the bleeding from fracture surfaces. The effect of commercially available pelvic circumferential compression devices on the reduction of symphysis pubis diastasis and the resuscitation has been proved. Prolonged use of these devices is complicated by the risk of development of pressure sores. Therefore prolonged immobilization on a spine board should be avoided. A number of different pelvic binders will be discussed in this article, which also presents a case.

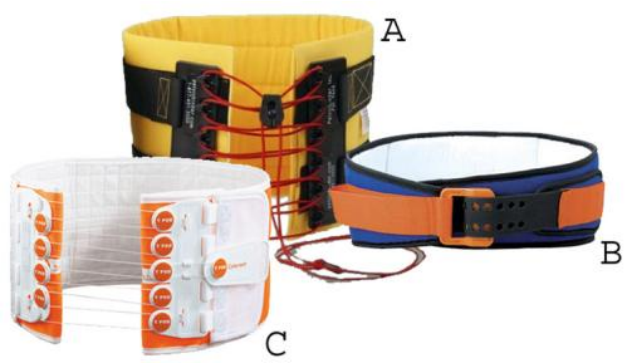

Figuur 1. a) Pelvic Binder ${ }^{\circledR}$; b) SAM-Sling ${ }^{\circledR}$; c) T-POD ${ }^{\circledR}$.

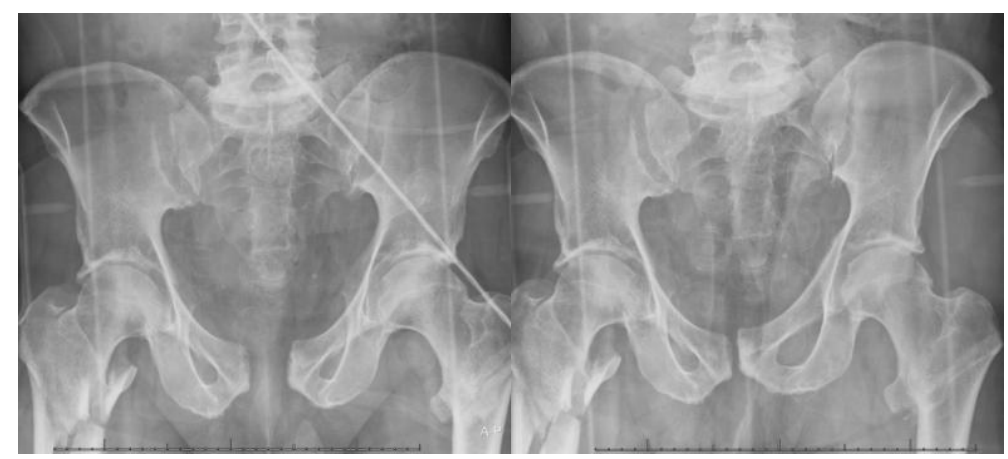

Figuur 2. Open-boek bekkenringfractuur: a) met evidente diastase van de symphysis pubis (30 mm);

b) met bekkenband (T-POD $\left.{ }^{\circledR}\right)$ en evidente reductie van de diastase van de symphysis pubis $(6 \mathrm{~mm}) \mathrm{na}$ aansnoering van de bekkenband. 